\title{
Development of an HPLC method for determination of pentachloronitrobenzene, hexachlorobenzene and their possible metabolites
}

\author{
Fazlurrahman Khan, Dhan Prakash and RK Jain ${ }^{*}$
}

\begin{abstract}
Background: Pentachloronitrobenzene (PCNB) and hexachlorobenzene (HCB) are highly toxic and widespread in every environmental compartment. Some of metabolic products such as amino/nitro containing chlorinated aromatic compounds can be determined by gas chromatography coupled with electron capture detector (GC$E C D)$. However, it is difficult to identify some of chlorophenolic and chloroquinolic intermediates produced from PCNB and HCB by the above mentioned technique. Therefore, for analysis of these compounds and their metabolites, we have developed a high performance liquid chromatography (HPLC) based method.

Results: The extraction of PCNB and HCB from soil and minimal salt medium was carried out with ethyl acetate and hexane respectively with good recoveries (98\% for PCNB and 97\% for HCB). The validation of the proposed extraction and HPLC method was done by analysis of PCNB and HCB biodegradation and their metabolites identification from anaerobic enriched soil samples.

Conclusion: A rapid, sensitive and simple HPLC based analytical method was developed for the analysis of PCNB, $\mathrm{HCB}$ and their possible intermediates.
\end{abstract}

\section{Background}

Farmers use pesticide (herbicides, insecticides, fungicides, molluscicides, rodenticides, acaricides and nematicides) for the protection of crop [1]. Chlorinated aromatic compounds (CACs) have been widely used in industrial, agricultural and domestic products such as pesticides, soil fumigants, disinfectants, toilet deodorants, solvents, and also used as precursors for the production of dyes [2,3].

As a result of worldwide extensive use, CACs are widespread and released as environmental pollutants in coastal marine sediments, freshwater lake sediments, sewage sludge, waste water, groundwater, rivers and estuaries, and soils [4-6]. Due to their persistence, toxicity, and bioaccumulation potential, CACs are subject to regulation in most of the developed countries [7]. The main environmental impact of pesticide is caused by their mobilization and transport from agriculture fields to pollute soils, sediment, water and also percolating through the soil and reaching the ground water [8-11].

\footnotetext{
* Correspondence: rkj@imtech.res.in
Institute of Microbial Technology (CSIR), Sector 39-A, Chandigarh-160036,

* Correspondence: rkj@imtech.res.in
Institute of Microbial Technology (CSIR), Sector 39-A, Chandigarh-160036, India
}

() Biomed Central

(C) 2011 Khan et al; licensee BioMed Central Ltd. This is an Open Access article distributed under the terms of the Creative Commons Attribution License (http://creativecommons.org/licenses/by/2.0), which permits unrestricted use, distribution, and reproduction in any medium, provided the original work is properly cited. nochlorine fungicide which has been widely use either for seed dressing or for soil treatment to control a wide range of phytopathogenic fungi in crops [12,13]. Hexachlorobenzene (HCB) is also used as a fungicide and is a side product of industrial emission related to the manufacture of chlorinated solvents and pesticides [14-16]. Both organochlorine fungicide (PCNB and $\mathrm{HCB}$ ) are widespread and found in every environmental compartment i.e. soil, water, and air $[17,18]$. Lipophilic nature of these compounds results in their bioaccumulation at different trophic levels via the food chain, thereby increasing risk to different living beings $[19,20]$. The accumulation of organochlorine pesticide is due to their resistance to both biotic and abiotic degradation in environmental condition [21]. Public concern has prompted the need for removal of these contaminants from the environment. Therefore, there has been an increase in effort to remove PCNB, $\mathrm{HCB}$ and their possible intermediates from the environment either by abiological or biological means during the past decades. The biotransformation products of PCNB include pentachloroaniline ( $\mathrm{PeCA})$, tetrachloroaniline 
(TeCA), trichloroaniline (TCA), dichloroaniline (DCA), chloroaniline (CA), pentachlorophenol (PCP), pentachlorothiophenol, pentachlorothioanisole and pentachloromethyl-phenyl sulfoxide [22-25]. The biotransformation products of $\mathrm{HCB}$ are pentachlorobenzene (PeCB), tetrachlorobenzene $(\mathrm{TeCB})$, trichlorobenzene $(\mathrm{TCB})$, dichlorobenzene (DCB), pentachlorophenol (PCP), tetrachlorohydroquinone $(\mathrm{TeCH})$ and dichlorohydroquinone $(\mathrm{DiCH})$ [14-16]. Some of these polychlorinated and their nitro or amino derivatives metabolites such as $\mathrm{PeCB}$, TeCB, TCB, DCB, PeCA, TeCA, TCA, DCA and CA can be determined by gas chromatography coupled with electron capture detector (GC-ECD) [26-29]. However, it is difficult to identify some of chlorophenolics and chloroquinolics intermediates such as PCP, tetrachlorophenol (TeCP), trichlorophenol (TCP), dichlorophenol (DCP) and $\mathrm{TeCH}, \mathrm{DiCH}$ by GC due to their relative polarity, low vapour pressure, chemical reactivity, causing adsorption and tailing of the chromatographic peaks [30,31]. Therefore, for determination of these CACs and chemically different nature (polar/ionic) of the putative intermediates, there is a need to develop simple, quick extraction and analytical method. In the present study we report a high performance liquid chromatography (HPLC) method for determination of $\mathrm{PCNB}, \mathrm{HCB}$ and their possible metabolites.

\section{Results}

\section{Solvents selection for extraction}

The solvents were selected for extraction of PCNB, HCB and their possible metabolites by dissolving increasing concentrations of compounds up to their maximum solubility into different organic solvents. Solubility tests revealed that all compounds were best soluble in ethyl acetate whereas HCB was only soluble in hexane. The selected solvents were used for the determination of extraction efficiency of PCNB, HCB and their possible metabolites.

\section{Extraction efficiency and quantification}

Quantitative determination of PCNB and HCB were performed by comparing peak areas of spiked soil with that of standards. Calibration graphs were constructed by plotting peak areas versus PCNB and HCB concentrations. Five working concentrations of $\mathrm{PCNB}$ and $\mathrm{HCB}$ compounds equivalent to $0.5,1.0,2.0,3.0$ and $4.0 \mu \mathrm{g}$ were added to 1 $\mathrm{ml}$ ethyl acetate and hexane respectively and analyzed in triplicate. A best linearity was found from the concentrations $0.5-4.0 \mu \mathrm{g} \mathrm{ml}^{-1}$ as indicated by correlation coefficient of 0.998 for both PCNB and HCB. Recoveries were studied by using five concentrations from $0.5,1.0,2.0,3.0$ to $4.0 \mu \mathrm{g}$ $\mathrm{ml}^{-1}$. The mean recoveries and relative standard deviation (R.S.D.) of PCNB and HCB are presented in the Table 1. The recoveries were found $98 \%$ for PCNB and $97 \%$ for HCB compounds.

To determine any interference caused by the endogenous and soil component, a blank soil sample was analyzed. No interference was identified from the soil sample. The limit of detection (LOD) were also calculated by applying the 3 s criterion equation: $y-y b=3 s b$, where as ' $y$ ' is lowest concentration signal and ' $y b$ ' is a blank signal, i.e. LOD corresponds to a signal equal to 3 times of standard deviation of the background noise. The detection limit for PCNB was found to be $0.0001 \mu \mathrm{g} \mathrm{ml}^{-1}$ and $0.0003 \mu \mathrm{g} \mathrm{ml}^{-1}$ for HCB. Similar exercise was carried out for both PCNB and HCB from MSM. Result indicated that extraction efficiency of PCNB and HCB from MSM was very close to the extraction efficiency as determined for the soil sample (data not shown).

\section{UV-vis absorption spectra and retention time of PCNB, HCB and their possible intermediates}

Identification of any aromatic compound by HPLC can be performed by comparing the UV-vis absorption spectra and retention time with the authentic standards. The retention time and UV-vis absorption spectra of PCNB, $\mathrm{HCB}$ and their possible intermediates are given in the Table 2. The proposed method is also well suitable for the identification of chlorophenolics and chloroquinolics intermediates such as PCP, TeCP, TeCH, TCP, and $\mathrm{DiCH}$.

\section{Method validation \\ Determination of PCNB, HCB depletion rate and identification of metabolites}

For validation of satisfactory results presented here, we applied this extraction and analytical method to determine PCNB, HCB depletion rates and also identification of metabolites from the PCNB and HCB enriched soil

Table 1 Recoveries (\%) of PCNB and HCB from spiked soil calculated by HPLC

\begin{tabular}{|c|c|c|c|c|c|c|c|}
\hline $\begin{array}{l}\text { Spiked concentration of } \\
\text { PCNB }\left(\mathrm{gm} \mathrm{kg}^{-1}\right)\end{array}$ & $\begin{array}{l}\text { Concentration (Mean } \pm \\
\text { SD) }\left(\mathrm{gm} \mathrm{kg}^{-1}\right)\end{array}$ & $\begin{array}{l}\text { RSD } \\
(\%)\end{array}$ & $\begin{array}{l}\text { Recovery } \\
\text { (\%) }\end{array}$ & $\begin{array}{c}\text { Spiked concentration of } \\
\text { HCB }\left(\mathrm{gm} \mathrm{kg}^{-1}\right)\end{array}$ & $\begin{array}{l}\text { Concentration (Mean } \pm \\
\text { SD) }\left(\mathrm{gm} \mathrm{kg}^{-1}\right)\end{array}$ & $\begin{array}{l}\text { RSD } \\
(\%)\end{array}$ & $\begin{array}{l}\text { Recovery } \\
\text { (\%) }\end{array}$ \\
\hline 0.05 & $0.0489 \pm 0.0016$ & 3.21 & 97.80 & 0.05 & $0.0488 \pm 0.0023$ & 1.45 & 97.60 \\
\hline 0.1 & $0.0979 \pm 0.0025$ & 2.84 & 97.79 & 0.1 & $0.0978 \pm 0.0025$ & 1.78 & 97.80 \\
\hline 0.2 & $0.1968 \pm 0.0016$ & 4.12 & 98.40 & 0.2 & $0.1957 \pm 0.0028$ & 2.10 & 97.85 \\
\hline 0.3 & $0.2976 \pm 0.0018$ & 1.83 & 99.20 & 0.3 & $0.2949 \pm 0.0053$ & 2.91 & 98.30 \\
\hline 0.4 & $0.3938 \pm 0.0013$ & 2.13 & 98.45 & 0.4 & $0.3937 \pm 0.0019$ & 2.24 & 98.42 \\
\hline
\end{tabular}


Table 2 Details of retention times and corresponding UVvis absorption spectra of PCNB, HCB and their possible intermediates determined by HPLC

\begin{tabular}{lll}
\hline Name of the compounds & Retention time $(\boldsymbol{m i n})$ & $\begin{array}{l}\text { UV-vis absorption } \\
\text { spectra }(\mathbf{n m})\end{array}$ \\
\hline PCNB & 6.692 & 301.0 \\
PeCA & 3.532 & 221.1 \\
TeCA & 5.375 & 308.5 \\
TCA & 4.121 & 248.1 \\
DCA & 6.951 & 246.9 \\
PCP & 5.780 & 303.7 \\
HCB & 22.88 & 290.7 \\
PeCB & 16.31 & 287.1 \\
TeCH & 3.735 & 297.8 \\
TeCB & 9.746 & 229.3 \\
TeCP & 4.520 & 299.0 \\
TCB & 12.06 & 268.2 \\
TeCNB & 4.266 & 223.4 \\
TCP & 3.966 & 289.5 \\
DCNB & 3.728 & 222.2 \\
DCB & 4.976 & 284.8 \\
DiCH & 4.214 & 277.6 \\
DCP & 3.457 & 281.2 \\
\hline
\end{tabular}

sample under anaerobic condition for up to a five months incubation period. Samples were drawn, extracted and analyzed at regular intervals by HPLC to determine the rate of depletion and appearance of intermediates. It was found that the rate of $\mathrm{PCNB}$ and $\mathrm{HCB}$ depletion increased with the time of incubation (data not shown). PCNB degradation intermediates viz; pentachloroaniline (PeCA), tetrachloroaniline (TeCA), trichloroaniline
(TCA) and dichloroaniline (DCA) from anaerobic enriched soil sample have been identified by HPLC with the retention time $3.532,5.375,4.121,6.951 \mathrm{~min}$ and UV-absorption spectra 246.9, 308.5, 248.1, $221.1 \mathrm{~nm}$ (Figure 1). There are few reports on degradation of PCNB by anaerobic mixed culture via reductive dechlorination under anaerobic condition $[22,25]$. Similarly, HCB degradation intermediates from anaerobic enrichment were identified as pentachlorobenzene (PeCB), tetrachlorobenzene (TeCB), trichlorobenzene (TCB) and dichlorobenzene (DCB) with the retention time 16.31, 9.746, 12.06, $4.976 \mathrm{~min}$ and UV-absorption spectra 287.1, 229.3, 268.2, $284.8 \mathrm{~nm}$ (Figure 2). The same HCB degradation metabolites have also been identified by reductive dechlorination in soil sediment [14]. There is one report on HCB degradation by Nocardioides sp. strain PD653, the identification of produced intermediates such as pentachlorophenol (PCP), tetrachlorohydroquinone $(\mathrm{TeCH})$, 2, 6-dichlorohydroquinone ( $\mathrm{DiCH})$ performed by $\mathrm{GC}$ after acetylation with acetic anhydride [26]. In the proposed method of identification of such phenolic intermediates by HPLC, there is no need of derivatization. The retention time and UV-vis absorption spectra of chlorophenolic and chloroquinolic standards such as pentachlorophenol (PCP), tetrachlorohydroquinone $(\mathrm{TeCH})$ and dichlorohydroquinone $(\mathrm{DiCH})$ was found to 5.780, 4.214, and 3.735 minute and 303.7, 297.8, 277.6 nm (Figure 3).

\section{Discussion}

Due to high electronegative properties of PCNB, $\mathrm{HCB}$ and their intermediates, the identification is possible by

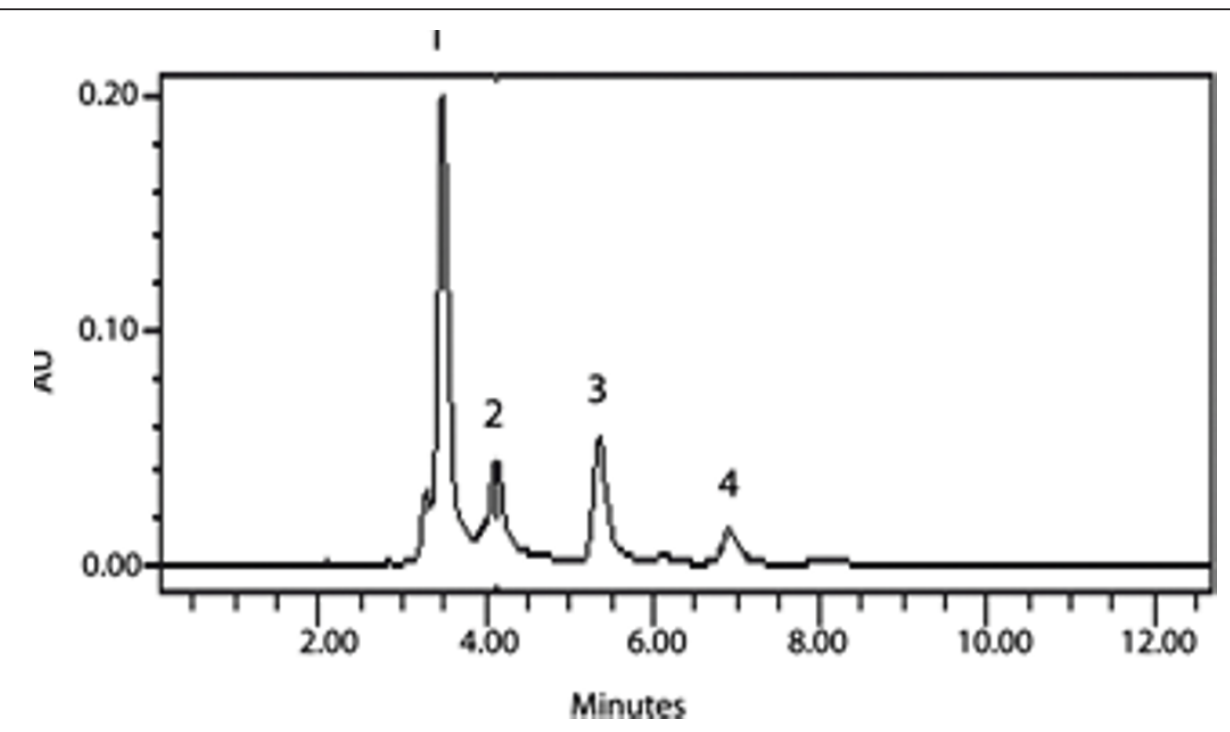

Figure 1 Representative HPLC chromatogram of PCNB metabolites identified from anaerobic enriched soil sample. Peak 1 , pentachloroaniline (PeCA); Peak 2, tetrachloroaniline (TeCA); Peak 3, trichloroaniline (TCA); and Peak 4, dichloroaniline (DCA). 


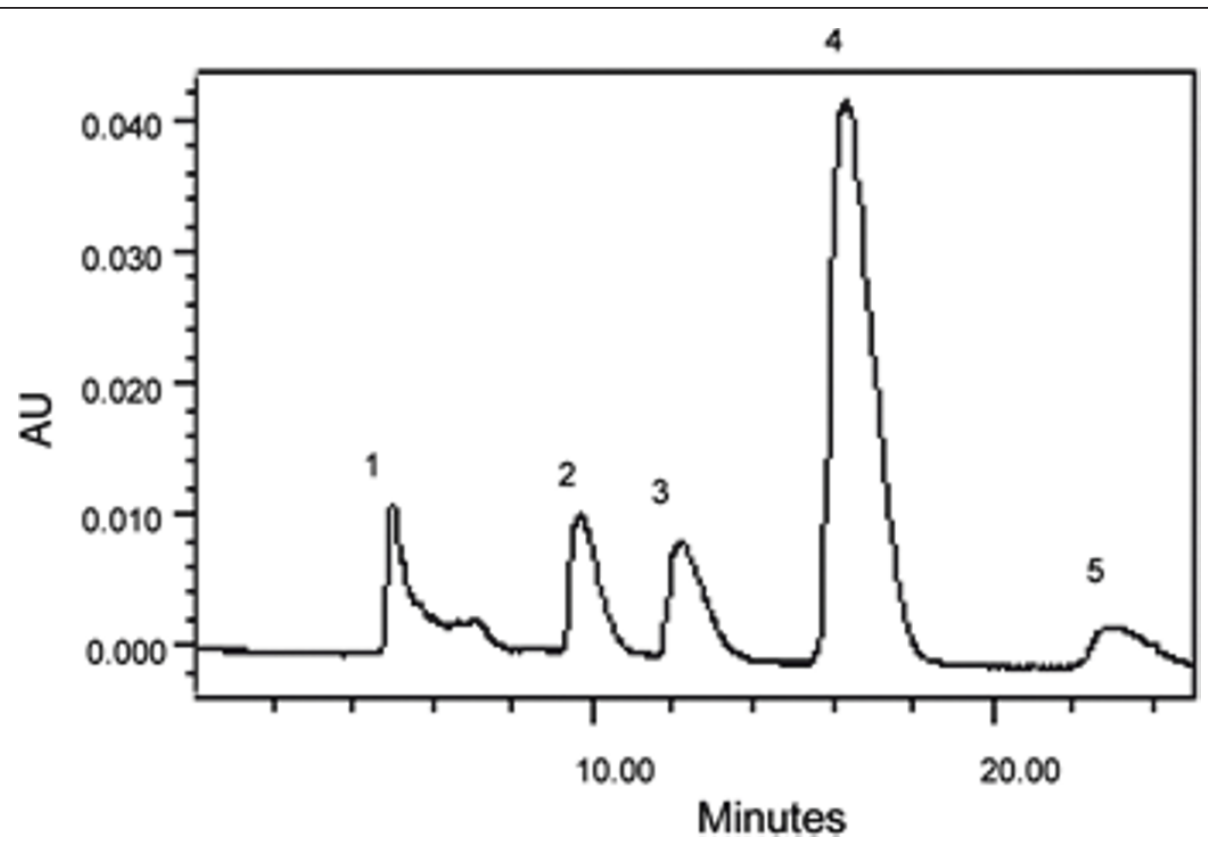

Figure 2 Representative HPLC chromatogram of HCB and their putative intermediates identified from anaerobic enriched soil sample Peak 1, dichlorobenzene (DCB); Peak 2, trichlorobenzene (TCB); Peak 3, tetrachlorobenzene (TeCB); and Peak 4, pentachlorobenzene (PeCB); and Peak 5-hexachlorobenzene (HCB).

gas chromatography coupled with electron capture detector (GC-ECD) and mass-spectroscopy (GC-MS) $[30,32,33]$. Although, the detection efficiency by these methods is good, yet there are several drawbacks like the need to derivatize such as methylation, acetylation and pentafluorobenzylation and the loss of compounds by thermal decomposition $[24,26,27,34]$. Similarly, there are a few reports describing extraction procedures for PCNB and HCB but they are cumbersome as they required additional steps, of sample cleanup or sample enrichment followed by quantitative determination by liquid chromatographic analysis [24,35]. In the present work, solubility analysis was carried out which indicated that all compounds were highly soluble in ethyl acetate, except HCB which was soluble in hexane. Based on their solubility, ethyl acetate and hexane were used for extraction of PCNB and HCB respectively from the soil sample as well as from the MSM. The proposed liquidliquid extraction and HPLC analysis procedure showed good recoveries of $98 \%$ with $0.0001 \mu \mathrm{g} \mathrm{ml}^{-1} \mathrm{LOD}$ for PCNB and $97 \%$ with $0.0003 \mu \mathrm{g} \mathrm{ml}^{-1}$ LOD for HCB without the need to cleanup the extracted samples. In the

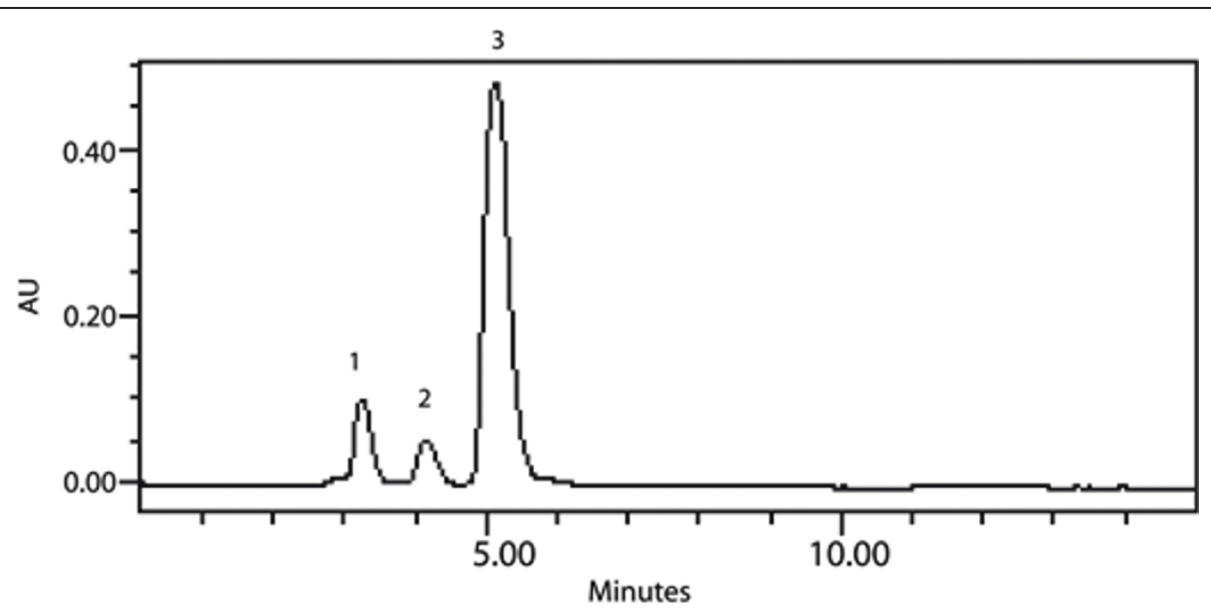

Figure 3 Representative HPLC chromatogram of chlorophenolics and chlorohydroquinolics standards showing; Peak 1, dichlorohydroquinone (DiCH); Peak 2, tetrachlorohydroquinone (TeCH); and Peak 3-pentachlorophenol (PCP). 
proposed HPLC method there is no need for the derivatization such as methylation, acetylation or pentafluorobenzylation for the detection of chlorophenolic and chloroquinolic intermediates. The proposed liquid-liquid extraction and analytical method is one of the most suitable for the application to any toxic organochlorine residue determination from different environmental compartment such as soil, sediment and sludge.

\section{Conclusion}

A rapid, sensitive and simple analytical method was developed for the determination of polychlorinated fungicides such as PCNB, HCB and their possible intermediates including chlorophenolic as well as chloroquinolic intermediates using HPLC techniques. The developed method gave good recoveries, good peaks resolution and sensitive detection levels without internal interference.

\section{Methods}

\section{Chemicals, reagents and standard stocks}

The standards of PCNB, HCB including their possible intermediates such as PeCA, PCP, TeCA, TCA, DCA, PeCB, TeCB, TeCH, TCB, TeCNB, TeCP), TCP, TCNB, DCP, DCNB, DCA, DiCH and DCB were purchased from Sigma Aldrich (St, Louis, MO, USA). Ethyl acetate, methanol, and hexane (HPLC grade) were obtained from Merck (Darmstadt, Germany). The stock solution $\left(100 \mu \mathrm{g} \mathrm{ml}^{-1}\right)$ of the above compounds was prepared in dimethyl sulphooxide (DMSO) of PCNB and in hexane of HCB. Stock solutions were diluted to obtain $10 \mu \mathrm{g} \mathrm{ml}^{-1}$ working solutions. All chemicals, aqueous solutions and standards were filtered through $0.22 \mu \mathrm{m}$ filter (Millipore, Milford, Mass., USA) and stored at $4{ }^{\circ} \mathrm{C}$. The composition of minimal salt medium (MSM) used for determining the extraction efficiency of PCNB and HCB compounds was the same as described by Fazlurrahman et al. [36].

\section{Sample preparation and fortification}

Soil samples (collected locally) were air dried, homogenized, grounded, sieved and stored in stoppered glass flasks at $18^{\circ} \mathrm{C}$. Fifteen gram soil sample was fortified by adding five working concentration of $\mathrm{PCNB}$ and $\mathrm{HCB}$ equivalent to $0.05,0.1,0.2,0.3$ and $0.4 \mathrm{mg} \mathrm{kg}^{-1}$ respectively. The standard solution(s) was mixed in $20 \mathrm{ml}$ MSM and added to the soil verifying that the solution covered the soil particles completely. After fortification, the samples were mixed with the help of glass rod followed by vortexing and kept in dark at room temperature for $24 \mathrm{~h}$ for equilibration. Since most of the microbial degradation of pesticide were also carried out in MSM, therefore the extraction efficiency of PCNB and HCB was also estimated from $10 \mathrm{ml}$ MSM containing 0.5, 1.0, 2.0, 3.0 and $4.0 \mu \mathrm{g}$ $\mathrm{ml}^{-1}$ respective compounds.

\section{Extraction efficiency of PCNB and HCB compounds from different sources}

For extraction, $15 \mathrm{~g}$ of the soil sample containing the standard compounds was blended with $45 \mathrm{ml}$ of ethyl acetate for PCNB and $45 \mathrm{ml}$ of hexane for HCB, vortexed vigorously for $10 \mathrm{~min}$ and centrifuged for $10 \mathrm{~min}$ at $15000 \mathrm{rpm}$. The upper organic phase was collected and evaporated to dryness in rotary evaporator at $45-50^{\circ}$ C. Extraction was repeated three times and the residues were re-dissolved in $1 \mathrm{ml}$ of their suitable solvent. The same procedure of extraction for the added PCNB and $\mathrm{HCB}$ to the MSM was performed by adding equal volume of ethyl acetate for PCNB and hexane for HCB. Similarly, the same extraction and analytical method were adapted for the extraction and analysis of PCNB, HCB degradation and metabolites identification from the anaerobic enriched soil sample. Finally, extraction efficiency of PCNB and HCB from spiked soil sample and MSM was calculated with the help of following equation:

Percent extraction efficiency $=($ Peak area of extracted sample for $X \mathrm{mM} /$ Peak area of standard sample for $X \mathrm{mM}) \times 100$

\section{Chromatographic apparatus and conditions}

The liquid chromatographic system consisted of WaterHPLC 600 and multi-solvent delivery system pump with Waters 996 photodiode array detector (Waters, Corporation, Milford, MA, USA). A reverse phase Waters Spherisorb $5 \mu \mathrm{m} \mathrm{C}_{18}(150 \times 4.6 \mathrm{~mm})$ column (Waters, Corporation, Milford, MA, USA) was used as the stationary phase. The separation of analytes on HPLC was conducted by using $\mathrm{RPC}_{18}$ column with mobile phase methanol: water $(96: 4, \mathrm{v} / \mathrm{v})$ at a column temperature of

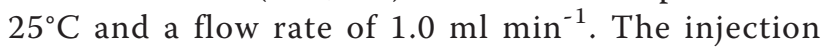
volume was $5 \mu \mathrm{l}$. The detection of the analytes was realized by measuring the UV-absorption with PDA detector at $300 \mathrm{~nm}$.

\section{Abbreviations}

(CACS): Chlorinated aromatic compounds; (PCNB): Pentachloronitrobenzene; (HCB): Hexachlorobenzene; (PeCA): pentachloroaniline; (TeCA): tetrachloroaniline; (TCA): trichloroaniline; (DCA): dichloroaniline; (CA): chloroaniline; (PCP): pentachlorophenol; $(\mathrm{PeCB})$ : pentachlorobenzene; $(\mathrm{TeCB})$ : tetrachlorobenzene; (TCB): trichlorobenzene; (DCB): dichlorobenzene; $(\mathrm{TeCH})$ : tetrachlorohydroquinone; and (DiCH): dichlorohydroquinone; (TeCP): tetrachlorophenol; (TCP): trichlorophenol; (DCP): dichlorophenol; (HPLC): high performance liquid chromatography; (PeCA): pentachloroaniline; (TeCA): tetrachloroaniline; (TCA): trichloroaniline; and (DCA): dichloroaniline; (TeCB): tetrachlorobenzene; and (GC-ECD): gas chromatography coupled with electron capture detector; and (GC-MS): mass-spectroscopy; (MSM): minimal salt medium.

\section{Acknowledgements}

We are thankful to Council of scientific and industrial research for financial support. This is IMTECH communication number 05/2010. 


\section{Authors' contributions}

FK and DP design the study, carried out the experiments, analyzed the experimental data and drafted the manuscript. RKJ conceived the project, coordinated it and refined the manuscript. All authors have read and approved the final manuscript.

Received: 24 December 2010 Accepted: 23 November 2011 Published: 23 November 2011

\section{References}

1. López-Pérez GC, Arias-Estévez M, López-Periago E, Soto-Gonzalez B, CanchoGrande B, Simal-Gándara J: Dynamics of pesticides in potato crops. J Agric Food Chem 2006, 54:1797-1803.

2. Golden KA, Wong CS, Jeremiasion JD, Eisenreich SJ, Hallgren J, Swackhamer DL, Engstrom DR, Long DT: Accumulation and preliminary inventory of organochlorines in Great Lakes sediments. Water Sci Technol 1993, 28:19-31.

3. Fetzner S: Bacterial dehalogenation. Appl Microbiol Biotechnol 1998, 50:633-657.

4. Oltmanns RH, Rast HG, Reineke W: Degradation of 1, 4-dichlorobenzene by enriched and constructed bacteria. Appl Microbiol Biotechnol 1988, 28:609-616.

5. Boyd EM, Killham K, Wright J, Rumford S, Hetheridge M, Cumming R, Meharg AA: Toxicity assessment of xenobiotic contaminated groundwater using lux modified Pseudomonas fluorescens. Chemosphere 1997, 35:1967-1985.

6. Wu Q, Milliken CE, Meier GP, Watts JEM, Sowers KR, May HD: Dechlorination of chlorobenzenes by a culture containing bacterium DF1, a PCB dechlorinating microorganism. Environ Sci Technol 2002, 36:3290-3294.

7. Adebusoye SA, Picardal FW, llori MO, Amund OO, Nathan Grindle CF: Aerobic degradation of di- and trichlorobenzenes by two bacteria isolated from polluted tropical soils. Chemosphere 2007, 66:1939-1946.

8. López Blanco MC, Cancho-Grande B, Simal-Gándara J, López-Periago E, Arias-Estévez M: Transport of commercial endosulfan through a column of aggregated vineyard soil by a water flux simulating field conditions. $J$ Agric Food Chem 2005, 53:6738-6743.

9. Bermúdez-Couso A, Arias-Estévez M, Nóvoa-Muñoz JC, López-Periago E, Soto-González B, Simal-Gándara J: Seasonal distributions of fungicides in soils and sediments of a small river basin partially devoted to vineyards. Water Res 2007, 41:4515-4525.

10. Pateiro-Moure M, Arias-Este'vez M, Lo'pez-Periago E, Martı'nez-Carballo E, Simal-Ga'ndara J: Occurrence and downslope mobilization of quaternary herbicide residues in vineyard-devoted soils. Bull Environ Contam Toxicol 2008, 80:407-411.

11. Pose-Juan E, Paradelo-Pérez M, Rial-Otero R, Simal-Gándara J, LópezPeriago JE: Detachment of sprayed colloidal copper oxychloridemetalaxyl fungicides by a shallow water flow. Pest Man Sci 2009, 65:615-623.

12. Okutman Tas D, Pavlostathis SG: The influence of iron reduction on the reductive biotransformation of pentachloronitrobenzene. Eur J Soil Biol 2007, 43:264-275.

13. U.S. Environmental Protection Agency (U.S. EPA): Reregistrartion Eligibility Decision for pentachloronitrobenzne, List A, Case No.0128; U.S.EPA. Office of Prevention, Pesticides and Toxic Substances: Washington, DC. 2006.

14. Fathepure BZ, Tiedje JM, Boyd SA: Reductive dechlorination of hexachlorobenzene to tri- and dichlorobenzenes in anaerobic sewage sludge. Appl Environ Microbiol 1988, 54:327-330.

15. Sala M, Ribas-fito N, Cardo E, de Muga ME, Marco E, Mazon C, verdu Grimalt JO, Sunyer J: Level of hexachlorobenzne and other organochlorine compounds in cord blood: exposure across placenta. Chemosphere 2001, 43:895-901.

16. Miyoshi K, Ishio T, Yasuhara A, Morita M, Shibamoto M: Detoxification of hexachlorobenzene by dechlorination with potassium-sodium alloy. Chemosphere 2004, 55:1439-1446.

17. Lievremont D, SeigleMurandi F, BenoitGuyod JL, Steiman R: Biotransformation and biosorption of pentachloronitrobenzene by fungal mycelia. Mycol Res 1996, 100:948-954.
18. Lopes TJ, Furlong ET: Occurrence and potential adverse effects of semivolatile organic compounds in streambed sediment, United States, 1992-1995. Environ Toxicol Chem 2001, 20:727-737.

19. Newhook R, Dormer W: Environmental Health Criteria 195: Hexachlorobenzene. WHO. 1997.

20. Arulmozhiraja SF, Shiraishi T, Okumura M, lida H, Takigami JS, Edmonds, Morita M: Structural requirements for the interaction of 91 hydroxylated polychlorinated biphenyls with estrogen and thyroid hormone receptors. Toxicol Sci 2005, 84:49-62.

21. González-López N, Rial-Otero R, Cancho-Grande B, Simal-Gándara J, SotoGonzález B: Occurrence of organochlorine pesticides in stream sediments from an industrial area. Arch Environ Contam Toxicol 2005, 48:296-302.

22. Murthy NBK, Kaufman DD: Degradation of pentachloronitrobenzene (PCNB) in anaerobic soils. J Agricul Food Chem 1978, 26:1151-1156.

23. Susarla S, Masunaga S, Yonezawa Y: Transformations of chloronitrobenzenes in anaerobic sediment. Chemosphere 1996, 32:967-977.

24. Torres RM, Grosset C, Alary J: Liquid chromatographic analysis of pentachloronitrobenzene and its metabolites in soils. Chromatographia 2000, 51:526-530.

25. Okutman Tas D, Pavlostathis SG: Microbial reductive transformation of pentachloronitrobenzene under methanogenic conditions. Environ Sci Technol 2005, 39:8264-8272.

26. Takagi K, Iwasaki A, Kamei I, Satsuma K, Yoshioka Y, Harada N: Aerobic mineralization of hexachlorobenzene by newly isolated pentachloronitrobenzene-degrading Nocardioides sp. strain PD653. Appl Environ Microbiol 2009, 75:4452-4458.

27. Cruz I, Wells DE: Determination of pentachlorophenol by exhaustive methylation and capillary gas chromatography in sewage sludge, contaminated water and suspended particulates. Int I Environ Anal Chem 1992, 48:101-113.

28. Tomkins BA, Merriweather R, Jenkins RA, Bayne CK: Determination of eight organochlorine pesticides at low $\mathrm{ng} / \mathrm{L}$ concentrations in groundwater using filter disk extraction and gas chromatography. J Assoc Offic Anal Chem 1992, 75:1091-1099.

29. Quayle WC, Jepson I, Fowlis IA: Simultaneous quantitation of sixteen organochlorine pesticides in drinking waters using automated solidphase extraction, high-volume injection, high-resolution gas chromatography. J Chromatographia 1997, 773:271-276.

30. Polese L, Ribeiro ML: Methods for determination of hexachlorobenzne and pentachlorophenol in soil samples. Talanta 1998, 46:915-920.

31. Zuin VG, da Silva Airoldi FP, do Nascimento NR, Landgraf MD, de O Rezende MO: Determination of pentachlorophenol and hexachlorobenzene in natural water affected by industrial chemical residues. J Braz Chem Soc 1999, 10:25-30.

32. Sheldon LW, Lucia RD, Roderick DI, Ulo K, Max LD: Residues of pentachlorophenol and other chlorinated contaminants in human tissues: Analysis by electron capture gas chromatography and electron capture negative ion mass spectrometry. Arch Environ Contam Toxicol 1991, 21:596-606.

33. Hong J, Rhee J, Kima T, Kim K: Simultaneous analysis of 25 pesticides in crops using gas chromatography and their identification by gas chromatography-mass spectrometry. J Chromatographia 1993, 639:261-271.

34. Boyd TJ: Identification and quantification of mono, di and trihydroxybenzenes (phenols) at trace concentrations in seawater by aqueous acetylation and gas chromatographic-mass spectrometric analysis. J Chromatogr A 1994, 662:281-292.

35. Jandera P, Fischer J, Prokes B: HPLC determination of chlorobenzne, benzenesulphonyl chloride and benzenesulphonic acids in industrial waste water. Chromatographia 2001, 54:581-587.

36. Fazlurrahman, Batra M, Pandey J, Suri CR, Jain RK: Isolation and characterization of an atrazine degrading Rhodococcus sp. Strain MB-P1 from contaminated soil. Lett Appl Microbiol 2009, 49:721-729.

doi:10.1186/1472-6769-11-2

Cite this article as: Khan et al:: Development of an HPLC method for determination of pentachloronitrobenzene, hexachlorobenzene and their possible metabolites. BMC Chemical Biology 2011 11:2. 